\title{
Supplementation of Vitamin A and D in the Medication of Lung Tuberculosis
}

\author{
Rita Dian Pratiwi ${ }^{1}$, Dibyo Pramono ${ }^{2}$, Iswanto ${ }^{3}$ Junaedi $^{4}$ \\ ${ }^{1}$ Department of Health Information Management, Universitas Gadjah Mada, Indonesia \\ ${ }^{2}$ Faculty of Dentistry, Universitas Gadjah Mada, Indonesia \\ ${ }^{3}$ Bethesda Hospital, Yogyakarta, Indonesia \\ ${ }^{4}$ National Population and Family Planning Board, Wonosobo District, Indonesia
}

\begin{abstract}
Article Info
Article history:

Received Jun 08, 2016

Revised Dec 18, 2016

Accepted Jan 17, 2017

\section{Keyword:}

Controlled Trial

Double Blinded Randomized

Lung Tuberculosis

Vitamin A

Vitamin D

ABSTRACT

At District of Wonosobo, Indonesia incidence rate of lung tuberculosis (TB) is increasing over years. In 2011 sputum conversion rate had reached 83.8\%. Incidence rate of lung TB is still relatively high. This is influenced by many factors, one of which is the process of transmission. Potential of transmission may still occur until end of intensive medication ( 2 months). Vitamin A and $\mathrm{D}$ as immunoprotection can be used as supplements that can accelerate sputum conversion. To find out effect of vitamin A and D supplementation in accelerating sputum conversion of lung TB patients during intensive phase. The study was true experimental (double blinded randomized controlled trial). Subject of the study consisted of two groups; one comprised as many as 30 positive acid fast bacillus lung TB patients supplemented with vitamin A at dosage of $1 \times 5000$ IU/day and vitamin D at dosage of $1 \times 400$ IU/day whereas another group was placebo during intensive phase. There was effect of vitamin A and D supplementation to acceleration of sputum conversion with score of $\mathrm{p} 0.003$; HR 2.45. Sputum conversion acceleration occurred in the experiment group during the second week with vitamin A and $\mathrm{D}$ supplementation as much as $86 \%$. Vitamin A and D supplementation could accelerate the incidence of sputum conversion as much as 2.45 times greater than placebo group; thus vitamin A and D could be used as complementary supplements in the medication of lung TB medication during intensive phase.
\end{abstract}

Copyright $(2017$ Institute of Advanced Engineering and Science. All rights reserved.

\section{Corresponding Author:}

Rita Dian Pratiwi,

Department of Health Information Management,

Gadjah Mada University,

Sekip 1, Bulak Sumur, Sleman Yogyakarta, Indonesia.

Email: ritadianp@ugm.ac.id

\section{INTRODUCTION}

Indonesia is included in 22 high-burden countries for lung tuberculosis (TB) and according to the Global Tuberculosis Control 2011 [1], in 2011 was ranked 4th from five countries with the highest TB burden - India, China, South Africa, Indonesia, and Pakistan. The prevalence of acid fast bacillus (AFB+) TB in Indonesia is 189 per 100,000 residents or about 430.000 cases [2]. The number of AFB+ cases detected in Central Java province in 2010 was $54.2 \%$ of all TB cases, under the target of $75 \%$. In Wonosobo district, the number of lung TB cases has increases every year. In 2011, there were 811 cases with 347 new AFB+ cases. In 2010, the conversion number was $86.6 \%$ which decreases to $83.8 \%$ in 2011 . Despite the conversion number meeting the required national standard, there are still a high number of TB cases for many reasons, one being its communicability, which can still occur towards the end of intensive medication ( 2 months).

It has been suggested that giving vitamin A and zink supplement to TB patients during treatment may optimize TB medication and sputum conversion by increasing body immunity and reducing mucus 
production in lungs [3],[4]. Vitamin A has many roles such as being imunoprotective against TB lung basil and protecting lymphocytes that stimulate nonspecific immunity such as macrophage activation. Low consumption of vitamin A can also causes low retinol plasma concentration, also reducing the body's immune response that can make TB worse [3],[5]. Vitamin D has the same immunity function as vitamin A in its ability to activate macrophages. The combination of vitamin A and D in normal dosages can increase the effectiveness of the immune system [6],[7], and can decrease $\mathrm{T}$ cell and B prolypherage and apoptosis [8].

For a TB patient, the faster the sputum conversion, the faster transmission can be prevented [2]. As vitamin $\mathrm{A}$ and $\mathrm{D}$ have similar immunoprotective functions, it has been suggested that they can be used as to fasten conversion [5],[9]. Therefore, the focus of this study is on combining vitamin A and D supplementation for lung TB patients. The objective is to determine the effect of vitamin A and D supplementation in accelerating sputum conversion of lung TB patients.

\section{RESEARCH METHOD}

A true experimental method was applied in this study. It was double blinded with the first group given vitamin A with dosage 1 x 5000IU/day and vitamin D 1 x 400 IU/day in a capsule made from soft gel, and group two was given a placebo. There were 30 patients selected in each group.

The study was conducted at every Primary Health Care (PHC) in Wonosobo region from November 2012 to April 2013, and intervention process up to 2 months for each respondent. The study population was patients newly diagnosed with TB with laboratory confirmation with microscope AFB (+) result. Inclusion criteria included: new patients, having AFB (+) result on microscopic research, more than 15 years old, can communicate well and able to visit the Wonosobo region Primary Health Care centers for medication. Exclusive criteria included having diabetes mellitus (based on rapid diagnostic test). During the study, if the subject consumed anti-TB medicine or other supplement or dropped out or was lost to follow, the subject will remain be evaluated in the end of the research.

To differentiate the treatment and placebo groups, participants were randomized using block permuted randomization method. This research uses 4 blocks there can be 6 possibilities such as AABB, BBAA, ABAB, BABA, BAAB, ABBA, with group $\mathrm{A}$ is the case group or group that is consume vitamin $\mathrm{A}$ and $\mathrm{D}$ supplement, while group $\mathrm{B}$ is control group that is given placebo.

The independent variable was supplementation with vitamin A and D and the dependent variable was sputum conversion. Bivariate analysis identified correlated variables, and multivariate analysis using the Cox regression proportional hazard test was then undertaken. Statistical analysis were done by using stata 11.0 and Microsoft exel.

\section{RESULTS AND ANALYSIS} in Figure 1.

There were 60 participants recruited, however 4 were lost to follow up or drop out. This is showed

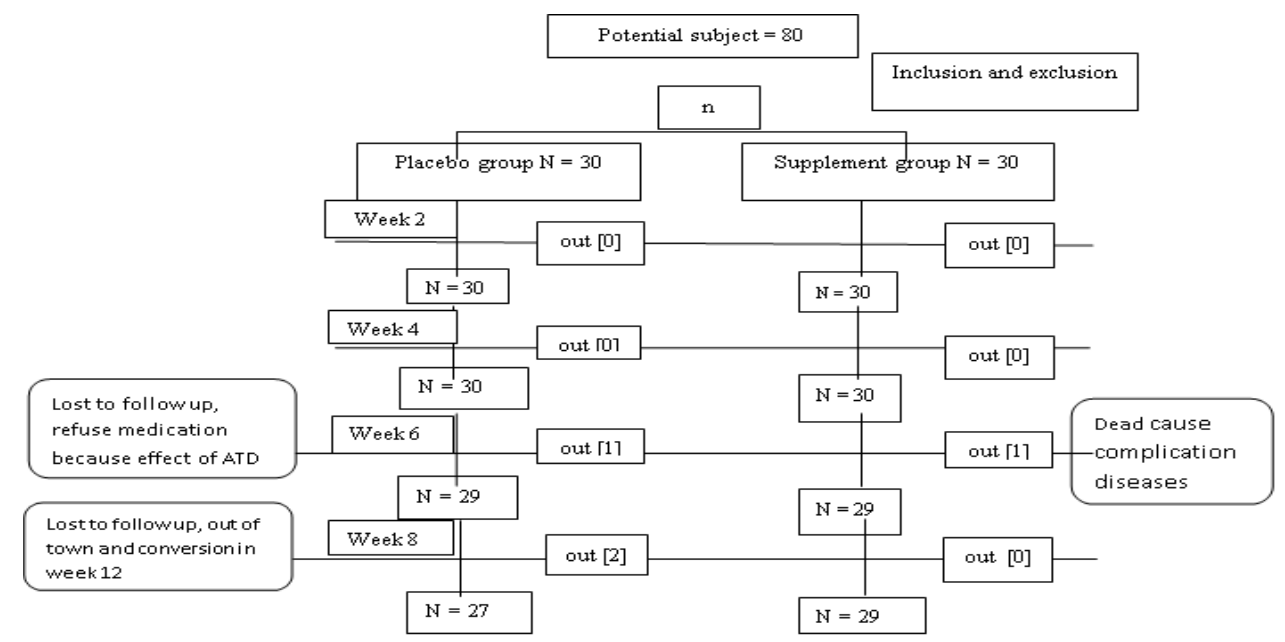

Figure 1. Randomized Control Trial Model in this Research 
The distribution of respondents based on age on treatment group is mostly on productive age that is between 16-30 years old, which is $56.67 \%$ (17 people). However, statistically there is no influence of age and conversion acceleration with $\mathrm{p}=0.64$ as shown in Table 2 . TB hinders socio-economic development, $75 \%$ of people with TB in the world are within the age 15 - 54 years, in countries where TB has gone from high to low incidence, it is mainly a disease of older people [7],[10]-[11].

This research found that age does not have any influence to sputum conversion. It is allegedly because of other factors that influence conversion such as the discipline of medicine taking. TB in Indonesia mostly attacks people in productive age, low income society and low education society [2].

This research found that male respondents are more than female, with a number of $60 \%$ (18 people). However, statistically there is no different conversion acceleration for both sex, with $\mathrm{p}=0.64$, this condition of the way body fight against tuberculosis is not different between male or female [1] as shown in Tables 1 and Table 2.

Table 1. Frequency of Demographic and Characteristic of Participants

\begin{tabular}{|c|c|c|c|}
\hline Variable & Treatment $(\mathrm{n}=30) \%$ & Placebo $(\mathrm{n}=30) \%$ & Total \\
\hline \multicolumn{4}{|l|}{ Age } \\
\hline$\leq 30$ & $17(57)$ & $9(30)$ & $26(43.3)$ \\
\hline$\geq 31$ & $13(43)$ & $21(70)$ & 34 (56.7) \\
\hline \multicolumn{4}{|l|}{ Sex } \\
\hline Female & $12(40)$ & $14(47)$ & $26(43)$ \\
\hline Male & $18(60)$ & $16(53)$ & $34(57)$ \\
\hline \multicolumn{4}{|l|}{ BMI (begin) } \\
\hline Normal & $11(37)$ & $8(27)$ & $19(32)$ \\
\hline Underweight & $19(63)$ & $22(73)$ & $41(68)$ \\
\hline \multicolumn{4}{|l|}{ BMI (week 8) } \\
\hline Normal & $16(53)$ & $13(42)$ & $29(49)$ \\
\hline Underweight & $14(47)$ & $17(58)$ & $31(51)$ \\
\hline \multicolumn{4}{|l|}{ Income } \\
\hline High $(\geq 824.000)$ & $9(30)$ & $5(17)$ & $14(23)$ \\
\hline Low $(<824.000)$ & $21(70)$ & $25(83)$ & $46(77)$ \\
\hline
\end{tabular}

Table 2. Logistic Regression Result of Demographic and Characteristics for each Groups by Time Hazard Ratio (HR)

\begin{tabular}{lcc}
\hline \multicolumn{1}{c}{ Variable } & HR (CI 95\%) & p-value \\
\hline Age : & $0.89(0.52-1.53)$ & 0.64 \\
<30 years & & \\
$>31$ years & $1.27(0.74-2.17)$ & 0.37 \\
Sex & $3.13(1.12-8.77)$ & 0.02 \\
regularity of medication & $2.07(0.97-4.44)$ & 0.05 \\
Frequency of medication & $1.31(0.76-2.28)$ & 0.32 \\
Side effects of drug & $1.68(0.91-3.09)$ & 0.09 \\
Income & $0.85(0.45-1.61)$ & 0.63 \\
Education & $2.84(0.69-11.7)$ & 0.14 \\
Supervisor of medication & $2.34(1.04-5.27)$ & 0.03 \\
BMI & & \\
Toxic : & $1.04(0.59-1.84)$ & 0.88 \\
Smoking & $2.25(0.53-9.50)$ & 0.26 \\
alcohol & & \\
\hline
\end{tabular}

*p value $<0.05$ significant, Hazard ratio $(\mathrm{HR})$ is the logistic regression measure by the time of event (acceleration sputum conversion)

The conversion acceleration is not interfered with the food intake is proofed by the fact that there is no influence of food intake both in treatment group and control group according to the statistic. Therefore, this research found that the nutrition status based on IMT can be caused by the intake of vitamin A and D supplement. There are 9 symptoms that mostly happen in respondent's body that is constant cough, breathless, chest pain, weak, low appetite, losing weight, malaise, sweating at night, and fever. The symptom will decrease in next two weeks [12]. The cough frequency and intensity will decrease after medication accordingly with body weight. However, in this research, in week 8 there are some respondents still cough constantly and with phlegm, breathless, weak feeling, losing appetite, malaise, and it is correlated with the AFB (+) grade experienced by respondents.

The side effect of medicine for most of respondents is nausea up to vomiting, and continuing up to week 4 with medication in some respondents. Effect of rimphampisin can cause nausea and vomiting in early 
stage of medication [13]. Some respondents experience pain on their legs and hands [14], the effect of pirazinamid given can cause pain on joints on $>5$ per 100 patients because the accumulation of uric acid.

Based on this research, it is known that there is significant influence of supplementation to conversion acceleration on TB medication in intensive phase, in which $\mathrm{p}=0.003$ and $\mathrm{HR}=2.45$ which means that each people on treatment group (given vitamin A and D) is 2.45 times more chances to experience conversion compared to control group with constant comparison for both groups. It is proven by the number of treatment group respondents with conversion in week 2 as many as $43 \%$ with the same AFB + grade on treatment group conversion in week 4 as shown in Figure 2.

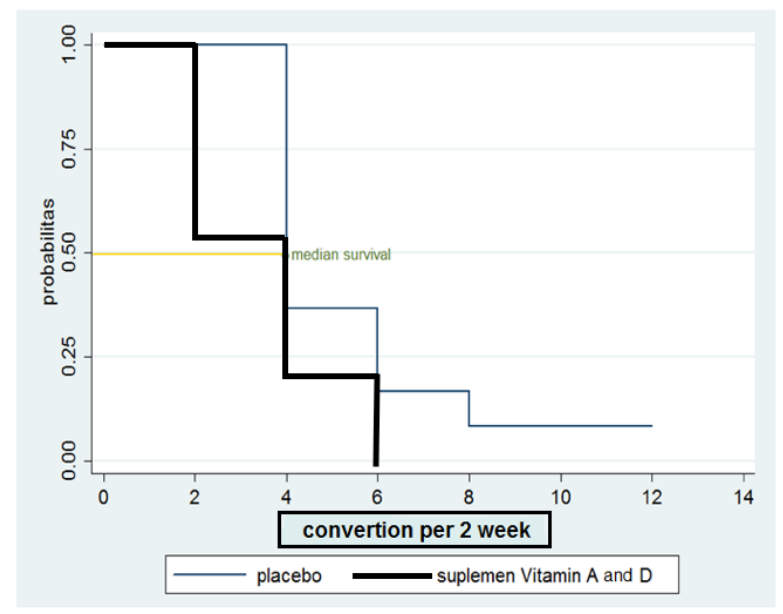

Figure 2. Kaplan Meier Curve Show Median Survival of Event (Acceleration Sputum Conversion)

The thick line represents for the supplement groups, they encounter the quickest event in week 2 and the longest in week 6 . The thin line represents for the placebo, they encounter the quickest event in week 4 and the longest in week 12. Based on the curve, the median event (acceleration sputum conversion) is in week 4 (Figure 2). Vitamins are essential constituents of our diet that have long been known to influence the immune system. Vitamins A and D have received particular attention in recent years as these vitamins have been shown to have an unexpected and crucial effect on the immune response [15].

Vitamin A in body can have function as immunity system that offensive in response on immunologic response as defense in which offensive protection will decrease inflammation incident while defensive mechanism will decrease duration/severity of inflammation [5],[16]. Supplementation with multiple micronutrients is more beneficial for treatment to patients with tuberculosis rather than vitamin $\mathrm{A}$ alone [17].

According to the research [8] which was done to 124 respondents in London, it is found that the effect of vitamin D3 consumption each month, compared to placebo, can accelerate the conversion in week 6. Vitamin $\mathrm{D}$ binding protein has multifunction, polymorphic $55 \mathrm{kDa}$ protein work as precursor from macrophage-activation factor and as co chemotaxin on phagocyte cells which indicated the role of chronic inflammation of lungs [8]. Vitamin D enhances host protective immune responses to Mycobacterium tuberculosis by suppressing Interferon-gamma (IFN-g) and reducing disease associated inflammation in the host [4],[18].

Vitamin D has ability to stimulate antimicrobial peptides secretion such as LL-37 (cathelicidin) and immunity system beta 4 in lungs [19]. Other than that is the existence of protection in immunity system that influence the differentiation of $\mathrm{T}$ cell that is Treg regulation and pro-inflammatory Th17, in which $\mathrm{T} 17$ is a simulator of inflammation gland and chemotasis neurophile which both of them are exist in lung tuberculosis [9]. The crucial role played by vitamin $\mathrm{D}$ in the immune response to $\mathrm{M}$. tuberculosis consists, as well as the production of the LL-37, in promoting phagolysosome formation [20].

Vitamin A and D also have similar role in immunity system. In addition, both of them are good antioxidant. Vitamin A and D can influence the immunity response with specific way [8],[17]. Both are active metabolite, retinoid acid, and 1, 25-dihydroxyvitamin D3 (1, 25 (OH) 2VD3) has characteristic as hormone. Both active metabolite, which are synthesized from precursor vitamin, are in different body tissue and cells and aimed at effect on distance target cell that tight hormone receptor. 
Vitamin A and D in their role to help sputum conversion acceleration on intensive phase of TB medication are supported by their functions on immunity system. T cells orchestrate a wide variety of immune responses. For a mature but naive $\mathrm{T}$ cell to become an effector $\mathrm{T}$ cell, the naive cell must receive multiple signals and integrate them effectively [17]. Retinoid and calsiferol can induct Treg and obstruct (inhibit) Th17 cell which emerges as the effect of Mycobacterium tuberculosis [16],[21]. Those are the depiction of the function similarity of vitamin $\mathrm{A}$ and $\mathrm{D}$ as hormone that stimulate $\mathrm{T}$ cell and they function as immunity system.

Most of respondents of this research are having low income, which is measured according to income compared to average of UMR (Regional Minimum Wage) in Wonosobo region and the result is $86.7 \%$. However, there statistic test shows that there is no significant correlation between income rate and TB with $\mathrm{p}=0.009$. According to [1] there are $90 \%$ of TB patients in the world are from low income society. The social economic condition is not the direct cause of TB cases or medication success, but it can influence the nutrition consumption, buying power, housing condition with is unhealthy and low access to medical service [2].

The desire to recover individual become strong suggestion to make someone discipline on medication. This research shows that there is significant correlation between the medication discipline with sputum conversion acceleration in bivariate test with $\mathrm{p}=0.02$ and after combining it with multivariate test, it shows $\mathrm{p}=0.13$. In TB control program, government applied DOT, which is helped with Medication Supervisors as shown in Table 2 and Table 3.

Table 3. Multivariate Analysis of Dominant Characteristics for each Groups by Time Hazard Ratio (HR)

\begin{tabular}{lcc}
\multicolumn{1}{c}{ Analysis model 1 } & HR multivariate (CI) & p-value \\
\hline Supplementation vitamin A and D & $2.04(1.27-4.52)$ & 0.007 \\
Income status & $1.11(0.56-2.20)$ & 0.760 \\
Regularity of medication & $3.16(0.70-14.2)$ & 0.130 \\
Supervisor of medication (PMO) & $0.92(0.17-4.86)$ & 0.920 \\
Nutrition status & $2.34(0.92-5.94)$ & 0.072 \\
Frequency of medication & $0.54(0.23-2.13)$ & 0.710 \\
Analysis model 2 & $2.45(1.36-4.39)$ & 0.003 \\
Supplementation vitamin A and D & $2.36(0.81-6.82)$ & 0.112 \\
Regularity of medication & $2.13(0.91-4.98)$ & 0.079 \\
Nutrition status & & \\
Analysis model 3* & $2.21(1.25-3.90)$ & 0.006 \\
Supplementation vitamin A and D & $3.12(1.11-8.73)$ & 0.030 \\
Regularity of medication & & \\
Analysis model 3* & $2.43(1.37-4.31)$ & 0.002 \\
Supplementation vitamin A and D & $2.68(1.18-6.11)$ & 0.018 \\
Nutrition status &
\end{tabular}

*Analysis model 2: to know the dominant characteristic which influence on the intervention process

*Analysis model 3: to know that regulation of medication and nutrition status is not the confounding for this study, with assumptions ion $\mathrm{p}$ value not more than $5 \%$ than crude analysis

However, PMO (Supervisor of Medication) has no influence on sputum conversion acceleration, it is because all respondents have PMO which most of them are the members of family (husband, wife, or children) and some others are supervised by TB medical officer who can prevent death, recurrence, and to cut the contagion chain and prevent the germs resistance to anti tuberculosis drug [2],[7].

\section{CONCLUSION}

There is influence of vitamin A and D supplementation to conversion acceleration with $\mathrm{HR}=2.45$. Vitamin A and D supplementation could accelerate the incidence of sputum conversion as much as 2.45 times; thus vitamin A and D could be used as complementary supplements in the medication of lung TB medication during intensive phase. It is important for TB officers to give counseling for society about the importance of consuming food, which contains vitamin A and D, especially for lung TB patients. It is also important for other researcher to develop this kind of research with bigger number of samples.

\section{ACKNOWLEDGEMENTS}

We would like to tahnk to: Dibyo Pramono from Faculty of Dentistry, Gadjah Mada University; Iswanto from Specialist of Pulmonary at Behesda Hospital; Junaedi from National Population and Family Planning Board, Wonosobo District, Indonesia. 


\section{REFERENCES}

[1] WHO, "Global Tuberkulosis control 2011," Available from: www.who.int/tb, 2011.

[2] Indonesia Ministry of Health, "National Strategy of TB Prevention in Indonesia 2010-2014," Jakarta, 2011.

[3] E. Karyadi, et al., "J.W.M A Double-blind, Placebo-controlled Study of Vitamin A and Zinc Supplementation in Person with Tuberkulosis in Indonesia, Effect on clinical response and nutrional status," Am J Clin Nutr, vol/issue: 75(4), pp. 720-727, 2000.

[4] S. Nawal, et al., "Vitamin D accelerates clinical recovery from tuberculosis: results of the SUCCINCT Study [Supplementary Cholecalciferol in recovery from tuberculosis]. A randomized, placebo-controlled, clinical trial of vitamin D supplementation in patients with pulmonary tuberculosis," BMC Infectious Deseases, 2013.

[5] B. R. Diness, et al., "Effect of high-dose vitamin A supplementation on the immune response to bacilli calmetteGuerin vaccine," Am J Clin Nutr, vol. 86, pp. 1152-1159, 2007.

[6] M. Adrian, "R IFN- $\gamma$ and TNF -independent Vitamin D-Inducible Human Supression of Mycobacteria: The Role of Cathelicidin LL-37," The Journal of Immunology, vol. 178, pp. 7190-7198, 2010.

[7] M. A. Hamburg and T. R. Freiden, "Tuberculosis transmission in the 1990's," The New England Journal of Medicine, vol. 330, pp. 1750-1751, 2001.

[8] Martineau A. R., et al., "High-dose vitamin D3 during intensive-phase antimicrobial treatment of pulmonary tuberculosis: a double-blind randomised controlled trial," Lancet, 2010.

[9] G. M. Hawthorne and D. R. Thickett, "Vitamin D and Tuberculosis," JPMI, vol/issue: 25(03), pp. 185-187, 2011.

[10] S. A. Corbett, et al., "Neutrophil mediated mycobacterial immunity in the lung during Mycobacterium bovis BCG infection in mice," Infection and Immunity, vol. 70, pp. 5322-5327, 2002.

[11] D. Webber and M. Kremer, "Stimulating industrial R \& D for neglected infectious diseases, economic perspectives," Health, vol. 8, pp. 693-801, 2001.

[12] O' Brien, et al., "Tuberculosis," Harrison's Pulmonary and Critical Care Medicine, The McGraw-Hill Companies, pp. 115-139, 2010.

[13] R. Geetha, et al., "Effect of rifampicin \& isoniazid on the steady state pharmacokinetics of moxifloxacin," Indian J Med Res, vol. 136, pp. 979-984, 2012.

[14] S. C. Rieder, "Interventions for tuberculosis control and elimination," Paris, IUATLD, 2002.

[15] M. J. Rodrigo, et al., "Vitamin effects on the immune system: vitamins A and D take centre stage," PMC, 2010.

[16] R. A. Catharine, "Vitamin A and retinoic acid in T cell-related immunity," Am J Clin Nutr, vol/issue: 96(5), pp. 1166S-1172S, 2012

[17] M. L. Mathur, "Role of Vitamin A Supplementation in the treatment of tuberkulosis," Natl Med J India, 2007.

[18] P. T. Liu, et al., "Cutting: edge vitamin D-mediated human antimicrobial activity against Mycobacterium tuberculosis is dependent on the induction of cathelicidin," J Immunol, vol/issue: 179(4), pp. 2060-2063, 2007.

[19] T. Najeeha, et al., "Vitamin D Deficiency and Tuberculosis Progression," Emerging Infectious Disease, 2010.

[20] C. Bedoya P. and Ronnenberg A. G., "Vitamin D and tuberculosis," Nutr Res, vol/issue: 67(5), pp. 289-93, 2009.

[21] D. Catia and B. Antonio, "The potential role of vitamin D for prevention and treatment of tuberculosis and infectious diseases,” Ann Ist Super Sanità, vol/issue: 48(3), pp. 319-327, 2012. 